\title{
Genetic dissection of Al tolerance QTLs in the maize genome by high density SNP scan
}

Claudia T Guimaraes ${ }^{1 *}$, Christiano C Simoes², Maria Marta Pastina', Lyza G Maron³, Jurandir V Magalhaes', Renato CC Vasconcellos², Lauro JM Guimaraes', Ubiraci GP Lana', Carlos FS Tinoco ${ }^{4}$, Roberto W Noda', Silvia N Jardim-Belicuas ${ }^{2}$, Leon V Kochian ${ }^{5}$, Vera MC Alves ${ }^{1}$ and Sidney N Parentoni ${ }^{1}$

\begin{abstract}
Background: Aluminum (Al) toxicity is an important limitation to food security in tropical and subtropical regions. High Al saturation on acid soils limits root development, reducing water and nutrient uptake. In addition to naturally occurring acid soils, agricultural practices may decrease soil pH, leading to yield losses due to Al toxicity. Elucidating the genetic and molecular mechanisms underlying maize Al tolerance is expected to accelerate the development of Al-tolerant cultivars.

Results: Five genomic regions were significantly associated with Al tolerance, using 54,455 SNP markers in a recombinant inbred line population derived from Cateto Al237. Candidate genes co-localized with Al tolerance QTLS were further investigated. Near-isogenic lines (NILs) developed for ZmMATE2 were as Al-sensitive as the recurrent line, indicating that this candidate gene was not responsible for the Al tolerance QTL on chromosome 5, qALT5. However, ZmNrat1, a maize homolog to OsNrat1, which encodes an $\mathrm{Al}^{3+}$ specific transporter previously implicated in rice Al tolerance, was mapped at $40 \mathrm{Mbp}$ from qALT5. We demonstrate for the first time that ZmNrat1 is preferentially expressed in maize root tips and is up-regulated by Al, similarly to OsNrat1 in rice, suggesting a role of this gene in maize Al tolerance. The strongest-effect QTL was mapped on chromosome 6 (qALT6), within a $0.5 \mathrm{Mbp}$ region where three copies of the Al tolerance gene, ZmMATE1, were found in tandem configuration. GALT6 was shown to increase Al tolerance in maize; the qALT6-NILs carrying three copies of ZmMATE1 exhibited a two-fold increase in Al tolerance, and higher expression of ZMMATE1 compared to the Al sensitive recurrent parent. Interestingly, a new source of Al tolerance via ZMMATE1 was identified in a Brazilian elite line that showed high expression of ZMMATE1 but carries a single copy of ZMMATE1.
\end{abstract}

Conclusions: High ZmMATE1 expression, controlled either by three copies of the target gene or by an unknown molecular mechanism, is responsible for Al tolerance mediated by qALT6. As Al tolerant alleles at qALT6 are rare in maize, marker-assisted introgression of this QTL is an important strategy to improve maize adaptation to acid soils worldwide.

Keywords: Genotyping-by-sequencing, MATE, Marker-assisted selection, Copy number variation

\footnotetext{
* Correspondence: claudia.guimaraes@embrapa.br

${ }^{1}$ Nucleus of Applied Biology, Embrapa Maize and Sorghum, Road MG424, km 65, Sete Lagoas, MG 35701-970, Brazil

Full list of author information is available at the end of the article
} 


\section{Background}

Aluminum (Al) toxicity is one of the major constraints for crop production on acidic soils, which comprise over $50 \%$ of the world's potentially arable lands [1]. Under low soil $\mathrm{pH}, \mathrm{Al}$ is solubilized into highly rhizotoxic ionic forms, primarily $\mathrm{Al}^{3+}$, that inhibit root growth, reducing water and nutrient uptake [2]. Although liming and other agronomic practices can ameliorate soil acidity, such technologies are not readily available for a large number of small-scale farmers particularly in the developing world, where agriculture is the main source of income and food. In addition to naturally occurring acid soils, soil acidification has been reported after 21 years of no-tillage crop system in the south of Brazil [3], an agricultural production method now largely adopted worldwide [4]. Maize is the most produced cereal in the world and is widely used in animal feed, human food and industrial purposes. In addition, maize is a major staple food in Africa and Latin America where acid soils are common [5]. Therefore, efforts to elucidate the genetic and molecular mechanisms underlying maize $\mathrm{Al}$ tolerance are expected to accelerate the development of Al-tolerant cultivars.

$\mathrm{Al}$ tolerance has been shown to be controlled by major genes in wheat [6], sorghum [7,8], and barley [9]. These plant species were used to clone the first $\mathrm{Al}$ tolerance genes, which were involved in organic acid exudation to exclude $\mathrm{Al}$ from the root apex. The $\mathrm{Al}$ tolerance gene in wheat encodes an aluminum-activated malate transporter (TaALMT1) responsible for malate release from root apices [6]. Subsequently, ALMT1 homologs with a role in Al tolerance were identified in Arabidopsis [10], rape [11], and rye [12]. Another gene family involved in Al tolerance is the multidrug and toxic compound extrusion (MATE) family that was originally associated with Al-activated citrate release in sorghum (SbMATE) [8] and barley (aluminum-activated citrate transporter 1, HvAACT1) [9]. In addition, MATE homologs confer $\mathrm{Al}$ tolerance in Arabidopsis (AtMATE) [13], wheat (TaMATE1) [14], rye (ScFRDL2) [15], maize (ZmMATE1) [16], and rice (OsFRDL4) [17].

Al tolerance is quantitatively inherited in Arabidopsis [18], maize [19-21], and rice [22-26]. Evidences for internal $\mathrm{Al}$ detoxification as a complementary $\mathrm{Al}$ tolerance mechanism have been supported by the identification of genes encoding ATP binding cassette transporters in Arabidopsis (ALS1 and ALS3) [27,28] and rice (STAR1, STAR2 [29]; OsALS1 [30]). Additionally, Nramp aluminum transporter 1 (Nrat1) is an aluminum transporter localized on the plasma membrane, which is required in the initial steps of internal $\mathrm{Al}$ detoxification in rice [31]. The expression of many genes involved in $\mathrm{Al}$ tolerance is regulated by a Cys2-His2 zinc finger transcription factor in Arabidopsis (STOP1) [32,33] and in rice (ART1) [34]. In fact,
ART1, STAR2 and Nrat1 co-localized with Al tolerance QTLs in rice [26], indicating that QTL mapping is a useful tool to help in the validation of candidate $\mathrm{Al}$ tolerance genes.

$\mathrm{Al}$ tolerance is a complex trait in maize [35-37], with possible involvement of multiple genes and physiological mechanisms. One such mechanism is root citrate release [38,39], although other mechanisms are likely to contribute to maize $\mathrm{Al}$ tolerance [40]. However, it is noteworthy that only a few QTLs [19-21] and candidate genes $[16,41,42]$ have been reported for $\mathrm{Al}$ tolerance on this crop. Combining association and linkage mapping, four candidate genes were associated with $\mathrm{Al}$ tolerance in maize, Zea mays $A_{l t_{S B}}$-like $(Z m A S L), Z m A L M T 2$, malic enzyme and S-adenosyl-L-homocysteinase [41]. However, functional characterization of ZmALMT2 did not support a role in maize Al tolerance [43]. Two maize homologs of sorghum SbMATE, ZmMATE1 and ZmMATE2, co-localized with Al tolerance QTLs [16] that were consistently detected in other QTL studies [19,20]. ZmMATE2 was not conclusively implicated in $\mathrm{Al}$ tolerance, but $Z m M A T E 1$ is up-regulated by $\mathrm{Al}$ and encodes a membrane transporter responsible for Al-activated citrate exudation in root apices of Al-tolerant maize lines [16]. Recently, three copies of ZmMATE1 were associated with high expression of this gene, which was proposed to underlie a major Al tolerance QTL mapped on maize chromosome 6 [42].

Here we performed a marker-trait association study with unprecedented marker density generated by genotypingby-sequencing (GBS) [44] to provide a detailed description of the genetic complexity underlying maize $\mathrm{Al}$ tolerance. Five QTLs highly associated with Al tolerance were identified with 54,455 single nucleotide polymorphisms (SNPs). Based on our results, ZmNrat1, which encodes a protein sharing high amino acid sequence identity with the rice $\mathrm{Al}^{3+}$ transporter, Nrat1, is a candidate gene for further $\mathrm{Al}$ tolerance studies in maize. We also validated a major $\mathrm{Al}$ tolerance QTL, qALT6, which was able to improve Al tolerance in maize NILs. Finally, a novel Al tolerance source in maize based on ZmMATE1 was identified, which does not rely on copy number variation to maintain high levels of ZmMATE1 expression.

\section{Results}

Multiple genomic regions are associated with Al tolerance in maize

Significant genotypic differences for relative net root growth (RNRG) were detected in the RIL population, which was used to assess $\mathrm{Al}$ tolerance. Net root growth in control conditions (NRG_c) was also assessed as a measurement of intrinsic differences in root growth that are not necessarily related to $\mathrm{Al}$ tolerance (Table 1 ). The heritability estimates based on family means were 0.94 
Table 1 Analyses of variance for relative net root growth and for net root growth in nutrient solution without $\mathrm{Al}$ in the recombinant inbred lines population

\begin{tabular}{llll}
\hline Source of variation & DF & MS & \\
\cline { 3 - 4 } & & RNRG & NRG_c \\
\hline Genotypes & 117 & $562.80^{* *}$ & $864.00^{* *}$ \\
Residual & 118 & 36.13 & 67.30 \\
Total & 235 & & \\
Coefficient of experimental variation (CVe\%) & 10.31 & 8.27 \\
Coefficient of genetic variation (CVg\%) & 27.84 & 20.12 \\
Heritability & 0.94 & 0.92 \\
CVg/CVe & 2.70 & 2.43
\end{tabular}

Relative net root growth: RNRG; Net root growth in nutrient solution without Al: NRG_c.

DF: degrees of freedom; MS: mean square; ${ }^{* *}$ significant at $p<0.01$

for RNRG and 0.92 for NRG_c, with a coefficient of variation close to $10 \%$ for both traits (Table 1 ).

Of the 458,255 SNPs generated with GBS, 54,455 SNPs were selected after imputing and filtering process (Additional file 1: Table S1). The imputation procedure improved by $43 \%$ the global number of SNPs, when compared with the selection of markers with less than $20 \%$ of missing data without imputing. Additionally, for chromosome 10, reducing MAF from 0.4 to 0.3 increased the number of SNPs from 694 to 2,803 , indicating a significant segregation distortion of GBS-based markers on this chromosome.

The QTL mapping approach detected five genomic regions significantly associated with $\mathrm{Al}$ tolerance on maize chromosomes 2, 3, 5, 6, and 8. Together, these QTLs explained approximately $63 \%$ of the total phenotypic variance for RNRG (Table 2 and Figure 1). Epistatic interactions were not detected with the current population size. Three candidate genes for $\mathrm{Al}$ tolerance previously described in maize, ZmMATE1, ZmMATE2 [16] and ZmASL [41] were genetically mapped to their predicted physical position based on anchored flanking SNPs. Two major Al tolerance
QTLs were found on chromosomes 3 (qALT3) and 6 (qALT6), which individually explained $\sim 27$ and $30 \%$ of the variation in RNRG, respectively (Table 2). All the alleles increasing $\mathrm{Al}$ tolerance were donated by the $\mathrm{Al}$ tolerant parent. Context sequences and SNP markers flanking each QTL were provided for approximately 200 bp windows defined based on the SNP markers with the highest $-\log _{10}(P$-value $)$ for association with $\mathrm{Al}$ tolerance (Additional file 2: Table S2).

Aluminum tolerance has been traditionally phenotyped based on the degree of root growth inhibition in Al-treated plants, relative to a $-\mathrm{Al}$ control, to remove possible confounding effects caused by intrinsic differences in root growth. To confirm that $\mathrm{Al}$ tolerance QTLs were not artifacts caused by variation in root growth unrelated to Al tolerance, QTLs were also mapped for NRG_c. Three genomic regions on chromosomes 1, 3, and 6 were associated with NRG_c, explaining approximately $57 \%$ of the total phenotypic variance (Table 3). Only the root growth QTL on chromosome 3 (qNRG_c3) was located near the Al tolerance QTL $q A L T 3$, but with opposite effects, indicating that for this QTL, selection to improve Al tolerance may cause a reduction in root length. Nevertheless, the other Al tolerance QTLs were not affected by root growth in the absence of $\mathrm{Al}$.

\section{Candidate genes on $9 A L T 5$}

qALT5 explained $17.6 \%$ of the phenotypic variance for RNRG and spanned a genomic region from 18.70 to 40.10 Mbp on chromosome 5. Based on the current annotation of the B73 RefGen_v2 genome sequence (5b.60), 432 gene models are predicted in this region, of which 30 were covered by at least one SNP significantly associated with Al tolerance (Additional file 3: Table S3). Among these genes, we selected $Z m M A T E 2$ predicted at $20.60 \mathrm{Mbp}$, which was previously characterized as a membrane transporter and putatively associated with $\mathrm{Al}$ tolerance in maize [16]. Maize NILs on the $\mathrm{Al}$

Table 2 QTLs identified through a multi-SNP regression model fitted with relative net root growth (RNRG) data

\begin{tabular}{|c|c|c|c|c|c|c|c|}
\hline QTL & Chr & SNP_ID & Position (Mbp) & $-\log _{10}(P)$ & Effect & $R_{P}^{2}(\%)$ & $\mathrm{Cl}(\mathrm{Mbp})$ \\
\hline qALT2 & 2 & S2_212940514 & 212.94 & 4.83 & 9.14 & 15.47 & $208.20-215.41$ \\
\hline qALT3 & 3 & S3_187460236 & 187.46 & 8.68 & 13.11 & 27.51 & $186.73-188.90$ \\
\hline qALT5 & 5 & S5_30301926 & 30.30 & 5.46 & 9.82 & 17.56 & $18.70-40.10$ \\
\hline qALT6 & 6 & ZmMATE1 & 5.86 & 9.74 & 14.21 & 30.54 & $5.44-5.96$ \\
\hline qALT8 & 8 & S8_22681622 & 22.68 & 6.17 & 10.43 & 19.86 & $17.06-27.64$ \\
\hline$R_{T}^{2}(\%)$ & & & & & & 62.78 & \\
\hline
\end{tabular}

Chr: maize chromosome; SNP_ID indicates the chromosome followed by the physical position in bp; ZmMATE1 is the sequence-tagged site marker developed within ZmMATE1.

The position of each QTL was determined in Mbp (Mega base pairs) as the highest $-\log _{10}(P$-value).

$R_{P}{ }^{2}(\%)$ is the percentage of the phenotypic variance explained by each QTL and $R_{T}{ }^{2}(\%)$ is the percentage of the phenotypic variance explained by the full model, including all significant QTLs.

$\mathrm{Cl}$ is the $95 \%$ confidence interval of the QTL position. 


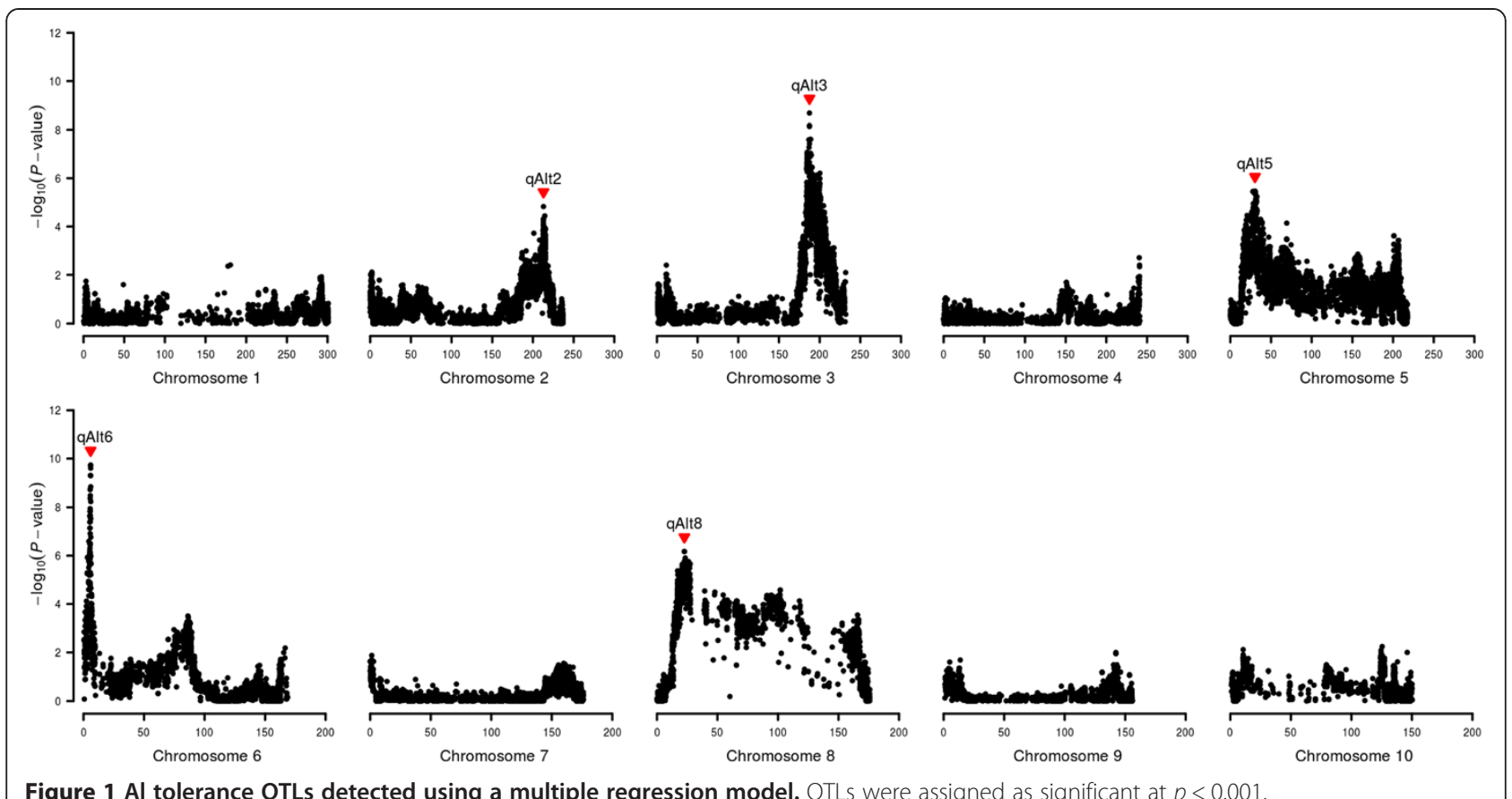

Figure 1 Al tolerance QTLs detected using a multiple regression model. QTLs were assigned as significant at $p<0.001$.

sensitive background belonging to L53 introgressed with ZmMATE2 were as Al-sensitive as was L53 (Figure 2a), and showed similar ZmMATE2 expression levels to the parents (Figure 2b). ZmMATE2 was not differentially expressed between the parental lines (Figure $2 \mathrm{~b}$ ), as reported by Maron et al. [16]. However, when the expression pattern of ZmMATE2 was investigated in the RILs, one expression QTL (eQTL) explaining 19.9\% of the variance for ZmMATE2 expression was revealed at 204.66 Mbp on chromosome 3 (Additional file 4: Figure S1a), a position different from the target gene on chromosome 5 .

Interestingly, another peak was detected close to qALT5, at $69.30 \mathrm{Mbp}$, but it was not significant in the multi-SNP regression model (Figure 1 ). In the vicinity of this putative peak, we identified the predicted gene GRMZM2G168747 at $74.61 \mathrm{Mbp}$, sharing $83 \%$ of amino acid sequence identity to rice Nrat1. The tissue specificity of ZmNrat1 was then evaluated after 6 hours of $\mathrm{Al}$ exposure in both parental lines (Figure 3a). The results demonstrate that ZmNrat1 is highly induced by $\mathrm{Al}$ in root tips, moderately expressed in basal root segments (1 to $3 \mathrm{~cm}$ above root tip) and is not expressed in shoots. A detailed time course response to Al treatment of root tips revealed that $Z m N r a t 1$ was up-regulated by $\mathrm{Al}$ at very early stages in the tolerant line, reaching the maximum level after 1 hour of $\mathrm{Al}$ treatment, whereas in the Al-sensitive line the highest expression was achieved 3 hours after exposure to Al (Figure 3b).

\section{Candidate genes on qALT6}

A highly significant QTL region was detected from 5.44 to $5.96 \mathrm{Mbp}$ (qALT6), explaining a large proportion of the variation in $\mathrm{Al}$ tolerance. This genomic region encompassed ZmMATE1 although none of the 54,455 SNPs tagged this candidate gene. Instead, a sequencetagged site (STS) marker generated within ZmMATE1

Table 3 QTLs identified through a multi-SNP regression model fitted with net root growth in nutrient solution without aluminum (NRG_C) data

\begin{tabular}{|c|c|c|c|c|c|c|c|}
\hline QTL & Chr & SNP_ID & Position (Mbp) & $-\log _{10}(P)$ & Effect & $R_{P}^{2}(\%)$ & $\mathrm{Cl}$ (Mbp) \\
\hline qNRG_Cl & 1 & S1_69700844 & 69.70 & 7.98 & -15.97 & 25.06 & $67.25-71.15$ \\
\hline qNRG_c3 & 3 & S3_195644732 & 195.64 & 10.50 & -18.97 & 32.18 & $187.71-195.96$ \\
\hline qNRG_c6 & 6 & S6_158261558 & 158.26 & 10.20 & -18.46 & 31.35 & $156.99-158.45$ \\
\hline$R_{T}^{2}(\%)$ & & & & & & 56.88 & \\
\hline
\end{tabular}

Chr: maize chromosome; SNP ID indicate the chromosome and the physical position in bp.

The position of each QTL was determined in Mbp (Mega base pairs) as the highest $-\log _{10}$ ( $P$-value).

$R_{P}{ }^{2}(\%)$ is the percentage of the phenotypic variance explained by each QTL and $R_{T}{ }^{2}(\%)$ is the percentage of the phenotypic variance explained by the full model, including all significant QTLs.

$\mathrm{Cl}$ is the $95 \%$ confidence interval of the QTL position. 

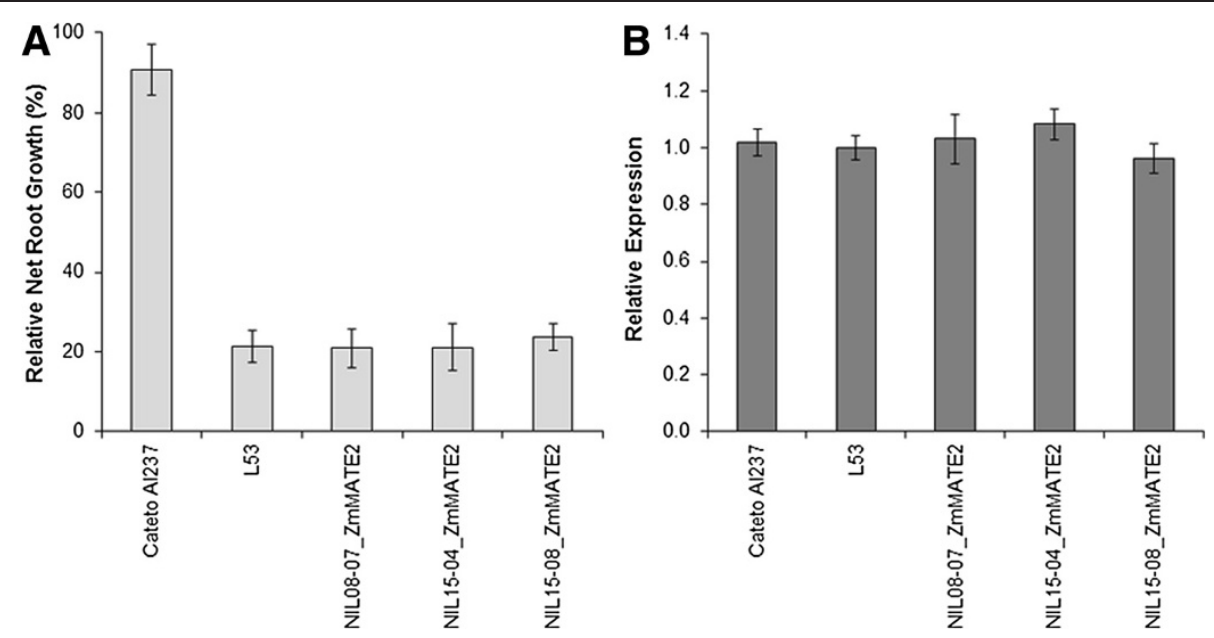

Figure 2 Near-isogenic lines introgressed with ZmMATE2, using Cateto Al237 and L53 as the donor and recurrent parents, respectively. A) Aluminum tolerance measured as relative seminal root growth after five days under $\{39\} \mu M \mathrm{Al}^{3+}$. B) ZmMATE2 relative expression evaluated in root tips after 6 hours of treatment with $\{39\} \mu \mathrm{M} \mathrm{Al}{ }^{3+}$. Expression of $L 53$ was used as calibrator. Error bars indicate standard deviation.
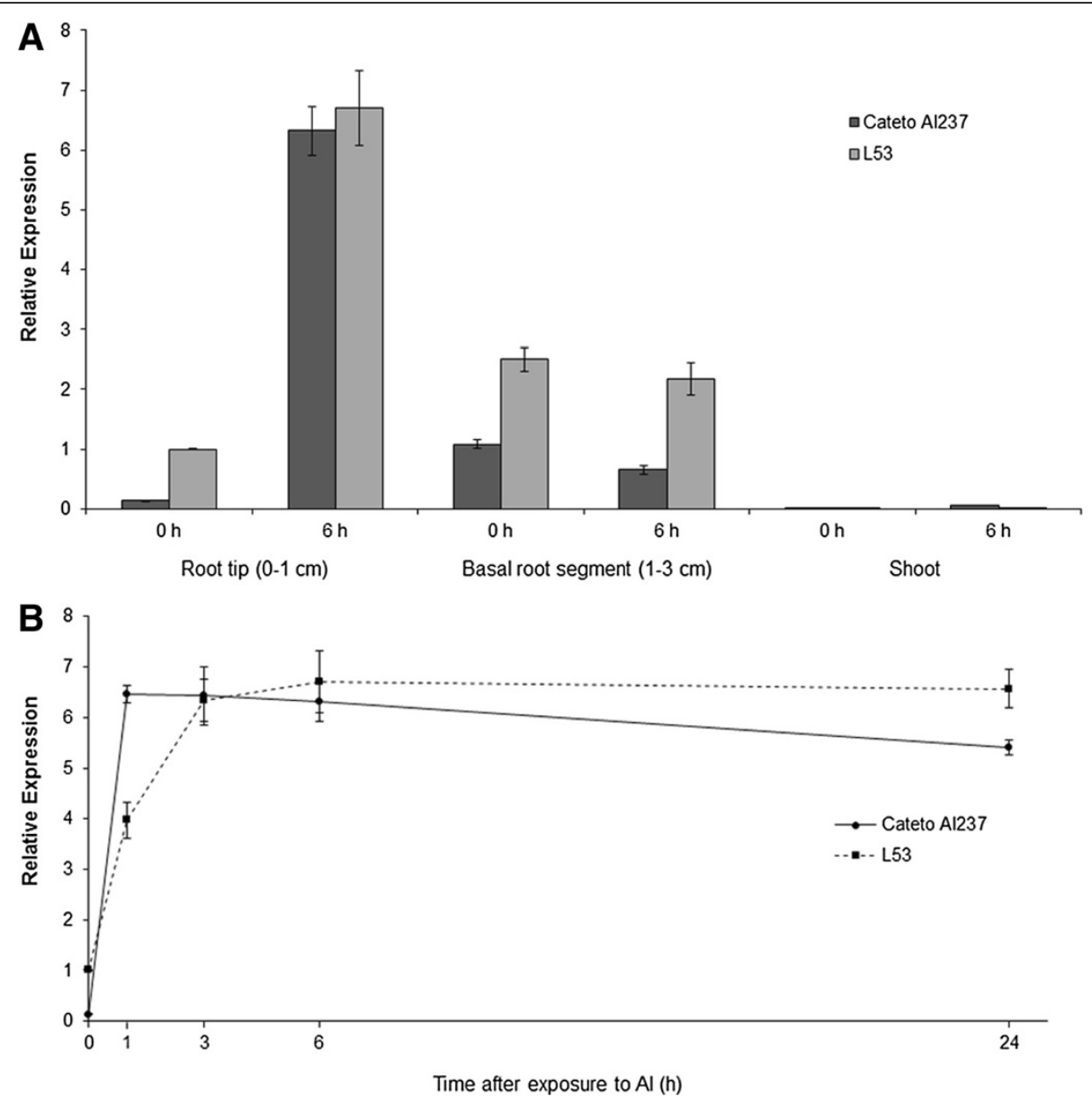

Figure 3 Spatial and temporal expression profiles of ZmNrat1 in two contrasting maize lines for Al tolerance. A) Expression of $Z m N$ rat1 in different tissues under controlled conditions, and after 6 hours at $\{39\} \mu \mathrm{M} \mathrm{Al}^{3+}$. B) Time course of $Z \mathrm{mNrat} 1$ expression following treatment of root tips with $\{39\} \mu \mathrm{M} \mathrm{Al}^{3+}$. Expression of $\mathrm{L} 53$ under controlled condition (-Al) was used as calibrator. Error bars indicate standard deviation. 
had the highest $-\log (P$-value) for RNRG (Table 2$)$. A single eQTL, explaining 70.9\% of the variance for ZmMATE1 expression, overlapped the qALT6 region where ZmMATE1 lies on chromosome 6 (Additional file 4: Figure S1b). This confirms previous results obtained at much lower SNP density, i.e. 1,894 SNPs on chromosome 6 [42].

The Cateto Al237 introgression region in the qALT6NILs was estimated as $10 \mathrm{Mbp}$, extending from positions 3.4 to 13.4 Mbp on chromosome 6. This region includes the STS marker for ZmMATE1 at position $5.86 \mathrm{Mbp}$, which showed the highest $-\log (P$-value $)$ with RNRG within qALT6. The qALT6-NIL harboring the Cateto Al237 allele showed a two-fold increase in Al tolerance when compared to the L53 counterpart (Figure 4a). The former exhibited also high ZmMATE1 expression (Figure 4b) and three copies of ZmMATE1, similarly to the donor parent Cateto Al237 (Figure 4c).

\section{Phylogeny of MATE members in maize}

Forty-three predicted MATE members found in the maize genome were clustered in two major groups, one of them comprising citrate transporters associated with $\mathrm{Al}$ tolerance in different plant species that included five maize MATEs (Additional file 5: Figure S2). These five predicted maize MATE proteins shared between 20 and 69\% sequence identity to SbMATE, including ZmMATE1 and ZmASL, which was previously associated with $\mathrm{Al}$ tolerance [41] (Additional file 6: Table S4). Of the five candidate MATE members analyzed, only ZmMATE1 was co-localized with Al tolerance QTLs mapped in this study.

\section{Identification of high ZmMATE1 expression in Brazilian maize lines}

High ZmMATE1 expression is associated with superior Al tolerance in maize RILs and NILs harboring the Cateto Al237 allele at qALT6. Thus, ZmMATE1 expression pattern under $\mathrm{Al}$ stress was investigated in 36 maize lines derived from the Embrapa breeding program including the intermediately $\mathrm{Al}$-tolerant, temperate maize line B73. The Embrapa elite lines showed a wide range of $\mathrm{Al}$ tolerance based on RNRG at $\{39\} \mu \mathrm{M} \mathrm{Al}^{3+}$, ranging from $\mathrm{Al}$-sensitive $(\mathrm{RNRG}<30 \%)$ to highly $\mathrm{Al}$-tolerant

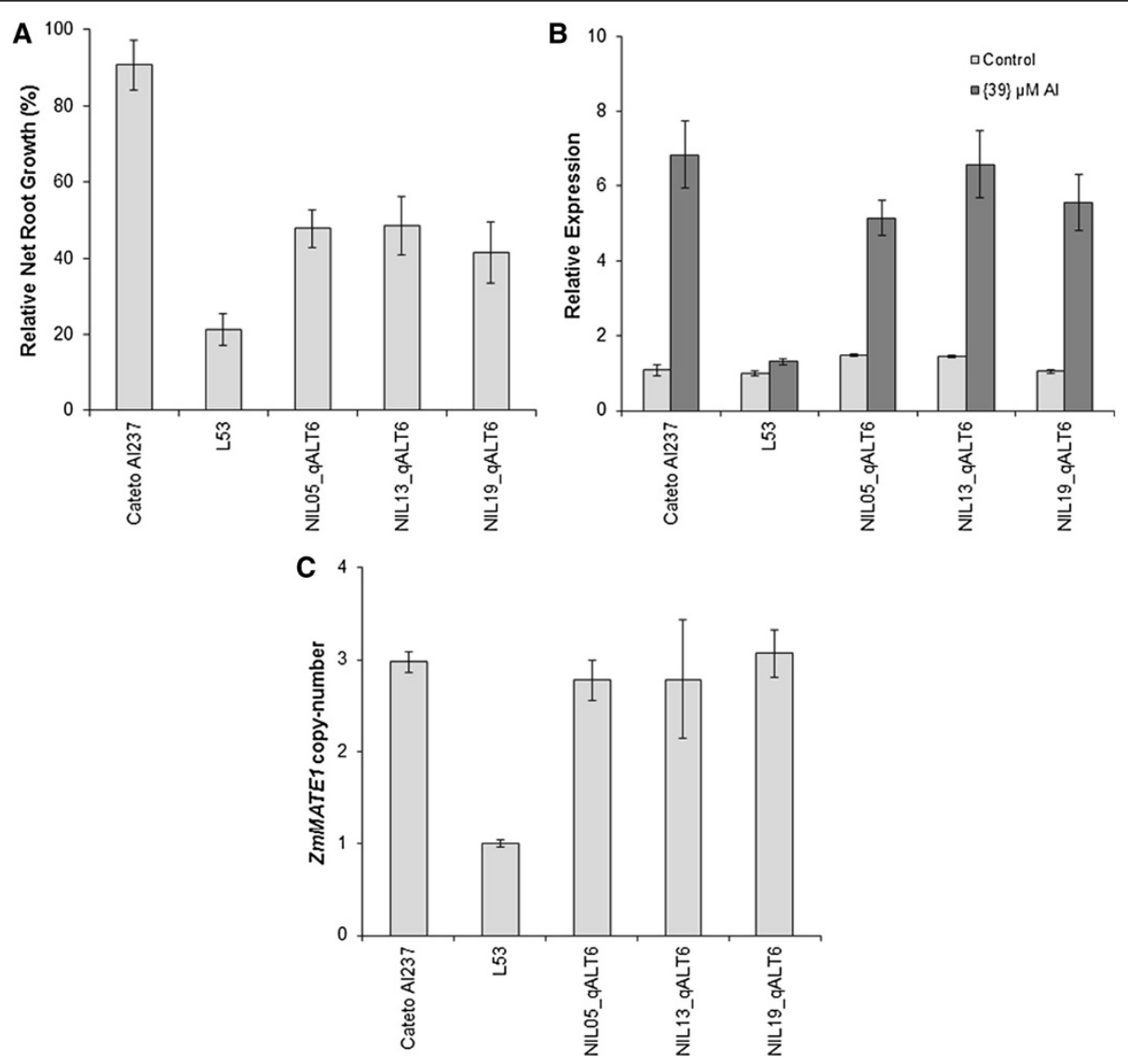

Figure 4 Near-isogenic lines introgressed with qALT6, using Cateto Al237 and L53 as the donor and recurrent parents, respectively. A) Aluminum tolerance measured as relative seminal root growth after five days under $\{39\} \mu M \mathrm{Al}^{3+}$. B) ZmMATE1 relative expression evaluated in root tips after 6 hours of treatment with $\{39\} \mu \mathrm{M} \mathrm{Al}^{3+}$ (dark gray) and under control condition (light gray). Expression of L53 under controlled condition (-Al) was used as calibrator. C) ZmMATE1 copy-number estimated based on qPCR. Error bars indicate standard deviation. 
(RNRG > 80\%) (Figure 5). The broad sense heritability estimate for Al tolerance was 0.95 , with an accuracy of 0.97. In addition to the highly tolerant Cateto Al237, seven lines in the panel showed high ZmMATE1 expression (Figure 5). These were L228-3 as well as six elite lines derived from L228-3, all of which are intermediately $\mathrm{Al}$-tolerant. Interestingly, L228-3 and its derived elite lines did not carry the three copies of ZmMATE1 reported for Cateto Al237 (Figure 6). The presence of a single copy of ZmMATE1 in these maize lines was indicated by two qPCR assays, CNV2 and CNV4, amplifying a fragment of the second exon and the 3'UTR region of ZmMATE1, respectively [42]. Thus, high expression of $Z m M A T E 1$ in these lines is likely mediated by a mechanism other than copy-number variation as proposed for Cateto $\mathrm{Al} 237$ [42].

\section{Discussion}

The genetic complexity of $\mathrm{Al}$ tolerance in maize was dissected using a large number of markers provided by nextgeneration sequencing in a RIL population derived from two highly contrasting maize lines. For QTL mapping, a procedure similar to multiple interval mapping was implemented, based on a multi-SNP regression model, which accommodated multiple QTLs simultaneously.

Five genomic regions were found to be highly associated with $\mathrm{Al}$ tolerance as measured by RNRG, including the novel QTL, qALT3. We also mapped a large-effect QTL for root growth under control (-Al) condition that was relatively close to qALT3 (qNRG_c3, at 195.64 Mbp on chromosome 3, Table 3). QTLs associated with root length were also previously mapped to a region surrounding qALT3 (171-179 $\mathrm{Mbp}$ on chromosome 3) $[45,46]$. Moreover, this region was flanked by two consensus QTLs, Rt-7 and Rt-8, which have been implicated in the control of several root traits in different maize populations [47]. Thus, although qALT3 does not overlap with $q N R G \_c 3$, further use of this Al-tolerance QTL in maize breeding programs may lead to the introgression of undesirable alleles for root length due to linkage drag.

The other four Al tolerance QTLs coincided with regions previously reported to be related to maize $\mathrm{Al}$ tolerance. The RFLP markers umc122 and umc49, located at 209.5 and 222.5 Mbp on chromosome 2, respectively, were associated with $\mathrm{Al}$ tolerance in five different maize crosses [48]. Also, an Al tolerance QTL was mapped in a genomic region equivalent to $198.8-211.2 \mathrm{Mbp}$ on maize chromosome 2 [20]. Despite the low saturation of markers used in these studies, it is plausible that these regions could be overlapping to qALT2 (211.2 - 215.4 $\mathrm{Mbp}$ ). Similarly, the Al tolerance QTL identified on chromosome 8 by Ninamango-Cárdenas et al. [20] is likely to correspond to qALT8.

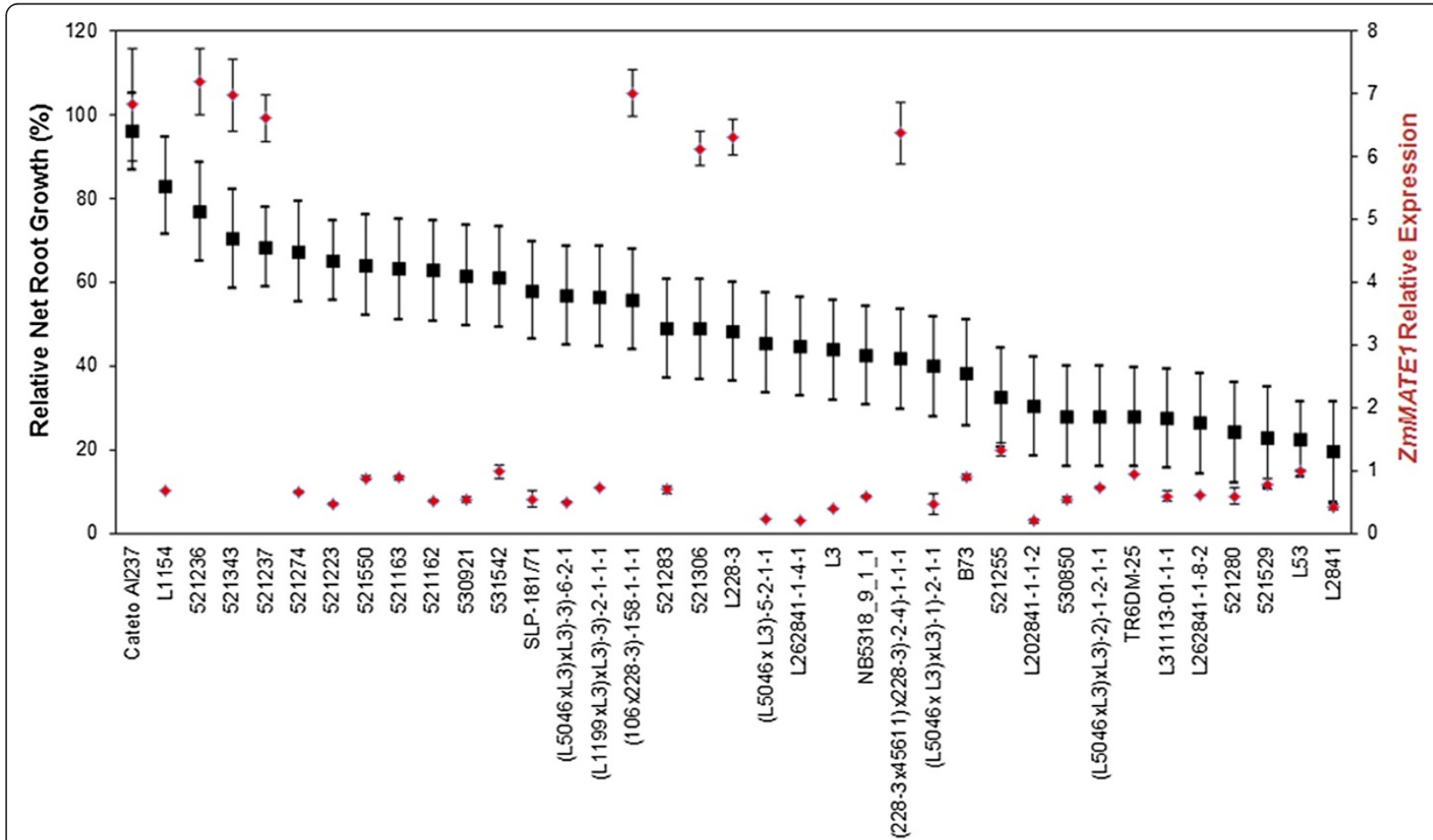

Figure 5 Aluminum tolerance and ZmMATE1 relative expression among 37 maize lines. Aluminum tolerance measured as relative seminal root growth after five days under $\{39\} \mu \mathrm{M} \mathrm{A{ } ^ { 3 + }}$ and ZMMATE1 relative expression evaluated in root tips after 6 hours of treatment with $\{39\} \mu \mathrm{M} A \mathrm{I}^{3+}$. 


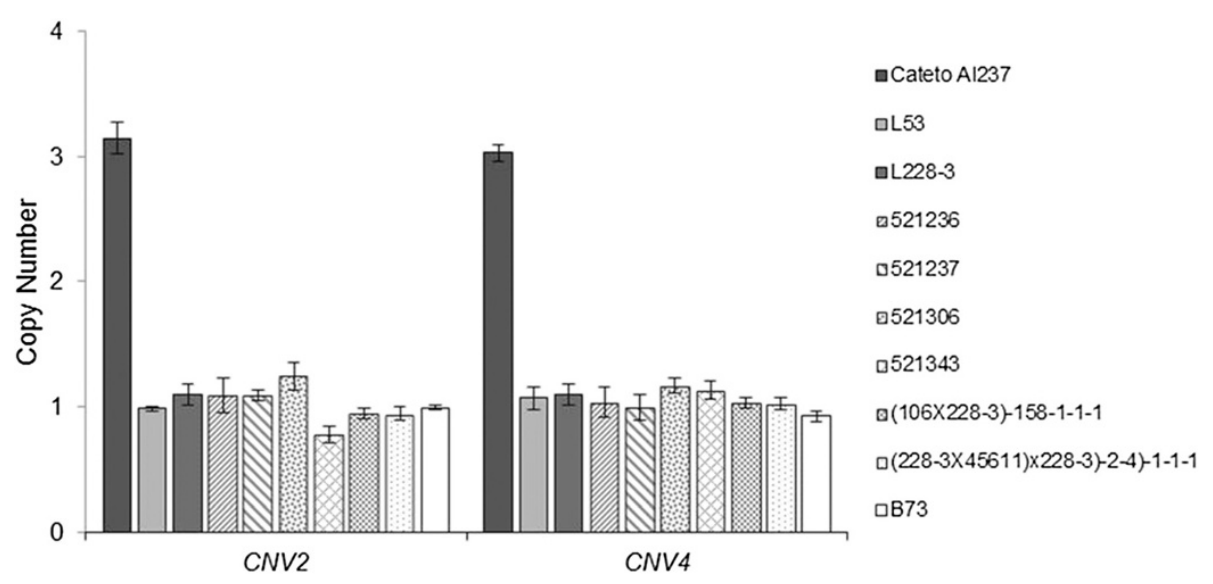

Figure 6 ZmMATE1 copy-number estimate based on quantitative PCR in Cateto Al237, L53, L228-3, L228-3-derived lines (line designations starting with numbers), and B73. The primers for CNV2 and CNV4 amplify a portion of exon 2 and $3^{\prime} U T R$ region of ZmMATE1, respectively.

The QTL, qALT5, reported here, was coincident with an Al tolerance QTL mapped on maize chromosome 5, which co-localized with ZmMATE2 [16]. This candidate gene was previously characterized as a putative anion transporter that was however unable to mediate citrate efflux [16]. This is consistent with the phylogenetic analysis where ZmMATE2 was not included in the major group composed of all MATEs functionally identified as citrate transporters in other plants (Additional file 5: Figure S2). To test the hypothesis raised by Maron et al. [16] that the Al-sensitive line, L53, would carry positive regulatory factors for ZmMATE2 expression, we mapped a trans-eQTL controlling part of ZmMATE2 expression on chromosome 3. Our data confirmed that maize NILs with the ZmMATE2 allele from Cateto Al237 in the genetic background of L53 showed the same ZmMATE2 expression level as the parental lines. Additionally, these maize NILs were as Al-sensitive as the sensitive recurrent line, L53. Thus, ZmMATE2 was constitutively expressed, independently of the source of trans-acting factors, either L53 or Cateto Al237. As ZmMATE2 amino acid sequences from Cateto Al237 and L53 were identical [16], we can infer that ZmMATE2 is not the candidate gene controlling $\mathrm{Al}$ tolerance on $q A L T 5$, at least in our maize germplasm.

Outside of the qALT5 confidence interval but near a putative QTL peak, we identified a maize homologue to rice Nrat1, named here as ZmNrat1. OsNrat1 encodes an Nramp aluminum transporter involved in intracellular $\mathrm{Al}^{3+}$ uptake in rice [31]. In our study, ZmNrat1 was up-regulated by $\mathrm{Al}$ primarily in root tips, following an expression pattern similar to that observed for the rice OsNrat1 [31]. However, the main difference found between the contrasting maize lines for Al tolerance was the early Al-induction of $\mathrm{ZmNrat1}$ in the Al-tolerant Cateto $\mathrm{Al} 237$. A previous report based on microarray analysis indicated that $\mathrm{ZmNrat1}$ was also induced by $\mathrm{Al}$ in root tips of the Al-tolerant Cateto 100-6 after 2, 6 and 24 hours of $\mathrm{Al}$ treatment and only after 6 and 24 hours in the Al-sensitive line (L53) [49]. Thus, these studies consistently showed that ZmNrat1 is rapidly induced by $\mathrm{Al}$ in tolerant maize lines (Cateto100-6 and Cateto Al237), whereas induction in the Al-sensitive line, L53, is delayed. Functional evidence in rice knockout mutants supported a role for Nrat1 in Al tolerance [31]. In addition, genomic regions surrounding this candidate gene on rice chromosome 2 were also shown to contribute to natural variation for $\mathrm{Al}$ tolerance in a biparental QTL mapping [23] and in the aus subpopulation in a genome-wide association study [26]. Nevertheless, the Nrat1 QTL region explained a low percentage of Al tolerance in a backcross introgression line population derived from temperate japonica $\mathrm{x}$ aus [23] and no QTL in this region was reported in a cross between tropical japonica and indica [26], suggesting that the effect of this QTL is dependent on the genetic background. The nonsignificance of the QTL peak spanning the ZmNrat1 region may be explained by: i) the presence of a significant QTL ( $q A L T 5$ ) close to this candidate gene that may have retained the genetic variance of this surrounding region; and ii) the reduced population size, which limits the power to resolve two closely linked QTLs. However, the evidence presented here warrants further investigation on the involvement of $Z m N r a t 1$ on the internal $\mathrm{Al}$ detoxification mechanism in maize.

The major Al tolerance QTL on chromosome 6 (qALT6) was also identified in other QTL studies [16,19,20]. Within this QTL region, we mapped ZmMATE1 as well as a major eQTL controlling its expression. The overexpression of $Z m M A T E 1$ was shown previously to improve Al tolerance in transgenic Arabidopsis [16]. Here we demonstrate that the high expression of ZmMATE1 almost 
doubled the Al tolerance of maize NILs when qALT6 was introgressed into an $\mathrm{Al}$-sensitive line. These NILs harbored three copies of ZmMATE1, confirming that the functional allele derived from Cateto Al237 was transferred. Interestingly, the expression pattern of ZmMATE1 in maize NILs was quite different from SbMATE in sorghum NILs, which was down-regulated when different alleles were introgressed into a common, Al-sensitive background [50]. This reduction in SbMATE expression was closely correlated with a decrease in Al tolerance, suggesting an incomplete transfer of regulatory factors acting in trans on SbMATE [50]. Marker-assisted introgression of SBMATE would be dependent on the genetic background and may require additional genomic regions carrying accessory factors necessary for the full expression of SbMATE. In maize, introgression of qALT6 seems to be enough for reaching full expression of ZmMATE1. Thus, our results, together with those presented in previous reports [16,42], strongly support that ZmMATE1 is the gene underlying qALT6, which enhances $\mathrm{Al}$ tolerance through its up-regulation under $\mathrm{Al}$ stress.

Cateto is a group of maize landraces from South America that were extensively adopted by native Indians and were also used as commercial varieties or in local hybrid programs [51]. Cateto lines were identified as highly Al-tolerant under field conditions [52] and in nutrient solution [53,54] in the early 1980's. Since then, Cateto lines have been considered as major sources of $\mathrm{Al}$ tolerance in maize. Three Cateto lines have been the subject of detailed genetic, physiological, and molecular studies of Al tolerance: Cateto Al237 [16,20,42,49], Cat100-6 [19,42,49,55,56], and Cateto Colombia [39,40]. The high Al tolerance of these lines in nutrient solution was mainly associated with an Al-exclusion mechanism mediated by $\mathrm{Al}$-activated citrate exudation in root tips $[16,39,40,42]$. Among those, only the native Brazilian lines, Cateto Al237 and Cat100-6, were confirmed to show high ZmMATE1 expression controlled by threecopies of this gene, which is considered to be the major molecular mechanism underlying citrate exudation in those lines [42]. As Cateto landraces were widely cultivated by natives and early farmers in South America [51], it is reasonable to expect that their extreme $\mathrm{Al}$ tolerance accounts for their superior adaptation to acid soils. However, these landraces carry undesirable traits, reducing their potential for direct use in commercial maize breeding programs [57]. Thus, the introgression of Al tolerance alleles from native races into maize elite lines is an important target to improve maize stability in tropical soils.

A further characterization of tropical maize lines revealed that L228-3 and its derived elite lines also presented high ZmMATE1 expression. However, in contrast to Cateto Al237 and Cat100-6 lines that carry this gene in triplicate [42], only a single copy of ZmMATE1 was found in L228-3 and its derived lines. L228-3 is the main founder of the dent heterotic group from the Embrapa maize breeding program [58], which was derived from the open pollinated variety BR106, as a result of 13 selection cycles in the Tuxpeño Composite [59]. Elite dent lines extracted from BR106 were used to develop commercial hybrids widely cultivated in Brazilian Cerrado, including BR201, a double cross hybrid that occupied up to $14 \%$ of the Brazilian seed market from 1989 to 1993 [60]. We can infer that, in L228-3, a different molecular mechanism to copy number variation (CNV) would enhance ZmMATE1 expression under $\mathrm{Al}$ stress, conferring an important advantage to acid soils adaptation.

\section{Conclusions}

The high ZmMATE1 expression controlled either by $\mathrm{CNV}$ or by another molecular mechanism that underlies $q A L T 6$, in addition to significantly improving $\mathrm{Al}$ tolerance in maize, is rare and restricted to a few South American landraces, mainly from Brazil and Colombia. Thus, we may expect that a large proportion of modern maize lines that range from $\mathrm{Al}$ sensitive to intermediate in $\mathrm{Al}$ tolerance could be improved for $\mathrm{Al}$ tolerance via marker-assisted introgression of this genomic region.

\section{Methods}

\section{Genetic stocks}

A population of 118 recombinant inbred lines (RILs) in S7, derived from a cross between Cateto Al237 and L53, was used for QTL mapping. Cateto Al237 and L53 have been characterized as highly $\mathrm{Al}$ tolerant and $\mathrm{Al}$-sensitive, respectively.

\section{Assessment of aluminum tolerance in nutrient solution}

Experiments were performed in a growth chamber at $27 / 20^{\circ} \mathrm{C}$ day/night temperatures, with light intensity of $330 \mu \mathrm{mol}$ photons $\mathrm{m}^{-2} \mathrm{~s}^{-1}$ and a $12-\mathrm{h}$ photoperiod. Maize seeds were surface-sterilized with $0.5 \%(\mathrm{w} / \mathrm{v})$ $\mathrm{NaOCl}$ for 5 minutes, thoroughly rinsed in deionized water and germinated for four days on moistened germination paper rolls. Seedlings were transferred to polyethylene cups placed into containers filled with $8.5 \mathrm{l}$ of nutrient solution at $\mathrm{pH} 4.0$, according to Magnavaca et al. [35], under continuous aeration, and acclimatized in full nutrient solution for $24 \mathrm{~h}$. After the initial root length (IRL) was measured, $+/-\mathrm{Al}$ treatments were imposed by replacing the nutrient solution with nutrient solution of identical composition but with or without \{39\} $\mu \mathrm{M} \mathrm{Al}^{3+}$ activity supplied as $\mathrm{KAl}\left(\mathrm{SO}_{4}\right)_{2}$. Free $\mathrm{Al}^{3+}$ activities (number in brackets) were calculated using the GEOCHEM-EZ speciation software [61]. The solution $\mathrm{pH}$ was adjusted to $\mathrm{pH}$ 4.0. After five days, the final root length (FRL) of each plant was measured. Net root 
growth (NRG) was calculated as NRG = FRL - IRL, either under $\mathrm{Al}$ treatment (NRG_Al) or under control condition, without Al (NRG_c). Finally, Al tolerance was expressed as Relative Net Root Growth (RNRG) estimated as RNRG = NRG_Al/NRG_c.

Experiments were performed in a complete randomized design with two replicates and seven plants per plot. Analysis of variance was performed using the Genes software [62].

\section{Molecular markers}

Genomic DNA was isolated from leaf tissue using the CTAB protocol [63]. Sequence-tagged site (STS) markers for candidate genes were designed based on polymorphisms detected in the parents. ZmMATE1 was genotyped with a 129-bp indel amplified with the primers 5'-CCGGATGTT TGCTGGATTTT-3' and 5'-TGGCCAAATCGACCATG ATT-3', and resolved on 1\% (w/v) agarose gel stained with ethidium bromide. ZmMATE2 was mapped with a 10-bp indel detected with the fluorescently labeled primers, $5^{\prime}$ GCAGTTCGTACGTAGTGGTG-3' and 5' -AGTACGTA GCTAGGCGATGC-3', in the ABI3100 genetic analyzer (Applied Biosystems). For ZmASL, the primers $5^{\prime}$-CCGG CACAGCAGTATCAAC-3' and 5'-TTGCTTTCCCCGA TAGAGAA-3' were designed based on reference sequences obtained from the Maize Assembled Genomic Island (MAGI) Database [64], which detected a 25-bp indel in the parents. ZmNrat1 [MaizeGDB: GRMZM2G069198] was genotyped using a Cleaved Amplified Polymorphic Sequence (CAPs) marker based on a genomic fragment amplified with primers 5'-CGCGGAAACAGGAACCAA ACCAAAA-3' and 5'-CGGGTCTCTGCGTACCCCGA-3', cleaved with Hinfl. The STS and CAPs markers described above were genotyped on $1 \%(\mathrm{w} / \mathrm{v})$ agarose gels.

SNPs were genotyped using genotyping-by-sequencing as described in Elshire et al. [44]. SNPs were designated with the letter $\mathrm{S}$ followed by the chromosome number and the physical position along each chromosome. Missing data imputation was performed with the software Npute [65]. SNP filtering was performed using the TASSEL software version 3.0.83 [66] with a minimum minor allele frequency (MAF) threshold of 0.4, except for chromosome 10 that was filtered using a minimum MAF of 0.3 , due to a high percentage of SNP markers showing segregation distortion.

\section{QTL mapping}

The procedure used for QTL mapping was similar to multiple interval mapping [67], which allows fitting multiple QTL simultaneously with main effects and epistatic interactions. The high marker density provided by GBS precluded the need for estimating conditional probabilities of marker genotypes.

First, a single marker analysis was performed using a linear regression model. Markers associated with $\mathrm{Al}$ tolerance were declared considering a $\mathrm{p}<0.001$ threshold. Next, a multiple regression model was fitted by adding the most significant SNP to the model selected in the preceding step. This was done in a stepwise fashion until no more significant SNPs were found. Finally, we tested all pairwise epistatic interactions among SNPs that were kept in the model as well as between those and all other SNPs.

SNP effects, partial $\left(R_{P}^{2}\right)$ and total $\left(R_{T}^{2}\right)$ coefficients of determination were estimated from a multi-SNP regression model. $R_{T}^{2}$ was calculated from the full model including all SNP effects, whereas $R_{P}^{2}$ was estimated for each SNP as follows. For a given significant SNP, we estimated the sum of squares of residuals from the reduced model (SSErm) without the SNP effect and the sum of squares of residuals from the full model (SSEfm). $R_{P}^{2}$ was estimated as 1-(SSEfm/SSErm). All QTL mapping procedure was implemented in the software R [68].

Information of SNP markers flanking each QTL were obtained from Panzea (http://www.panzea.org/db/searches/ webform/marker_search). Markers were selected in a window size of approximately $200 \mathrm{bp}$ to the SNP associated with $\mathrm{Al}$ tolerance at highest $-\log _{10}(P$-value $)$.

\section{Development of NILs for the two major Al tolerance QTL}

RIL-150 and RIL-84 were selected based on the presence of the Cateto Al237 allele at the Al tolerance QTLs, qALT6 and qALT5, respectively. These RILs were crossed with the Al sensitive recurrent parent, L53, following two cycles of marker-assisted backcrosses and selfing until $\mathrm{BC}_{2} \mathrm{~F}_{3}$ progeny fixed for the $\mathrm{Al}$ tolerance QTL were obtained. For $q A L T 6$, foreground selection was based on a STS marker for ZmMATE1 and the SSR marker, umc1018, whereas for $q A L T 5$ we used only the STS marker for ZmMATE2. Background selection was performed using $\sim 30$ simple sequence repeats (SSR) markers randomly distributed along the maize genome, which allowed for the selection of NILs with 98\% of the L53 genome. NILs for qALT6 were genotyped-bysequencing to evaluate the size of the Cateto Al237 introgression.

\section{Expression pattern of ZmMATE1, ZmMATE2 and ZmNrat1}

Temporal and spatial expression profiles of the candidate genes were obtained using quantitative real-time PCR (qPCR), after 6 hours of Al treatment. For this analyses, the first centimeter of root apices were sampled as previously described [16]. Expression of ZmNrat1 was also assessed in a root segment extending from 1 to $3 \mathrm{~cm}$ from the root tip, which was designated as basal root segment, and in shoot tissues. The time-course profile for ZmNrat1 expression in root tips was obtained after 1, 3, 6 and 24 hours of exposure to $\{39\} \mu \mathrm{M} \mathrm{Al}^{3+}$, and compared to the control lacking Al. Total RNA was 
extracted using the RNeasy Plant Mini Kit (Qiagen) according to the manufacturer's instructions. First-strand cDNA was synthesized using the High Capacity cDNA Reverse Transcription Kit (Life Technologies). ZmMATE1 expression was determined using a custom-designed TaqMan assay consisting of forward primer $5^{\prime}$-CACCCGCT TAGCGTATTCCT-3', reverse primer 5'-GCACCGCGA TCCTCATGAT-3' and probe 5'-TCTGAATGCGAGCC TCG-3', with a pre-designed TaqMan assay for Eukaryotic 18S (Life Technologies) as endogenous control [42]. ZmMATE2 expression was evaluated using a TaqMan assay according to Maron et al. [16]. The expression profile of ZmNrat1 was conducted using the Fast SYBR ${ }^{\circ}$ Green Master Mix (Life Technologies) with primers F: 5' CGCGCTTCTGATCCAAACA-3' and R: 5'-GCGAGA TGCTTGCCTGTCTT-3', with 18S RNA as endogenous control. qPCR reactions for ZmMATE2 and ZmNrat1 were conducted in an ABI 7500 Fast (Life Technologies). Each biological sample was composed by 21 plants and 3 technical replicates were adopted. Raw data were collected using the RQ Manager software (Life Technologies) and the relative expression levels were calculated using the ddCT method [69]. Relative expression data for ZmMATE1 and ZmMATE2 were used for expression QTL (eQTL) mapping.

\section{Copy number quantification for ZmMATE1}

Copy number for ZmMATE1 was estimated by qPCR using two primer pairs designed by Maron et al. [42] with the Fast $\mathrm{SYBR}^{\oplus}$ Green Master Mix in an ABI 7500 Fast (Life Technologies). The CNV2 assay was performed with primers F: 5'-CCAGGCTCGCATTCA GATG-3' and R: 5'-GCACCGCGATCCTCATG-3', and CNV4 with F: 5'-TGTGAGTTTGGCGGATGTGT-3' and R: 5'-TCACAATCTAGGCCAGTACAACAGA-3', both using the actin gene as a single copy control [42]. After optimization, the reactions were performed using $6 \mathrm{ng}$ of genomic DNA with $0.6 \mathrm{pmol}$ and $0.3 \mathrm{pmol}$ of primers for CNV2/CNV4 and the control, respectively. Three technical replicates were performed for each sample and assay. Relative quantification (RQ) was calculated by dividing the target sample quantity by the control sample quantity mean, then normalizing against the calibrator sample, L53, using the ddCT method [69].

Phylogenetic studies of MATE genes in the maize genome MATE proteins in the maize genome were identified by sequence similarity analysis using the Sorghum bicolor SbMATE amino acid sequence [GenBank: ABS89149.1] as query in the B73 RefGen_v2 filtered set (Maize Genome Sequencing Project, release 5b.60, www.maizesequence. org). The Peptide Homologs tool in Phytozome was used to confirm that all predicted maize MATEs were identified.
The amino acid sequences of maize MATEs as well as the MATE genes previously identified as Al tolerance genes in other crops, such as sorghum (SbMATE), Arabidopsis (AtMATE), rice (OsFRDL4), barley (HvAACT1), rye $(S c F R D L 2)$ and wheat (TaMATE1), were aligned using the Advanced M-COFFEE package available at TCOFFEE (www.tcoffee.org). The phylogenetic tree was constructed using maximum parsimony and 500 bootstraps with MEGA5 [70].

\section{Al tolerance in a maize panel}

Thirty six tropical maize inbred lines developed by the Embrapa Maize and Sorghum (Sete Lagoas, Brazil) breeding program, as well as the temperate maize line B73, were evaluated for Al tolerance. Linear mixed model analysis was performed using an incomplete block design with common checks and three replicates, considering genotypes and blocks as random effects and experiment as a fixed factor. The experimental unit consisted of seven plants per genotype. Two maize lines, L53 and Cateto Al237, were used as common checks in each experiment. The linear mixed model analysis was performed in the software SELEGEN-REML/BLUP [71] according to the model: $y=X t+Z g+W b+e$, where: $y$ is the vector of phenotypes; $t$ is the vector of experimental effects (fixed) plus the overall mean; $g$ is the vector of genotypic effects (random); $b$ is the vector of block effects (random); and $e$ is the error vector (random). $\mathrm{X}, \mathrm{Z}$ and $\mathrm{W}$ represent the incidence matrices for the effects of $t, g$ and $b$, respectively. The means and variances were structured and distributed as follows:

$$
\begin{aligned}
& y / t, \quad V \sim N(X t, V) \\
& g / \sigma_{g}^{2} \sim N\left(0, I \sigma_{g}^{2}\right) \\
& b / \sigma_{b}^{2} \sim N\left(0, I \sigma_{b}^{2}\right) \\
& e / \sigma_{e}^{2} \sim N\left(0, I \sigma_{e}^{2}\right)
\end{aligned}
$$

The genotypic values $(\mu+\mathrm{g})$ were used to characterize the $\mathrm{Al}$ tolerance of these lines, and the confidence intervals $(\mathrm{CI})$ were estimated using the standard error of the predicted genotypic values (SEP), which corresponded to the squared root of predicted error variance (PEV), according to the expression: $\mathrm{IC}=(\mu+\mathrm{g}) \pm \mathrm{t} \times \mathrm{SEP}$, where: $\mathrm{t}$ $(0.95)=1.96$ is the value of Student distribution at $95 \%$ of confidence interval. Non-overlapping confidence intervals indicate statistical differences of predicted genotypic effects in multiple comparisons.

\section{Additional files}

Additional file 1: Table S1. Genotyping-by-sequencing SNPs generated across the 10 maize chromosomes in the recombinant inbred line population. 
Additional file 2: Table S2. SNP markers flanking each Al tolerance QTL in a windows size of approximately $200 \mathrm{bp}$ to the SNP associated with Al tolerance at highest $P$-value.

Additional file 3: Table S3. Predicted genes from 18.70 to $40.10 \mathrm{Mbp}$ on chromosome 5, comprising the qALT5.

Additional file 4: Figure S1. Expression QTLS (eQTLS) of ZMMATE2 and ZMMATE1 on chromosomes 3 and 6, respectively.

Additional file 5: Figure S2. Maximum likelihood phylogenetic tree of maize MATE members and MATE proteins characterized as citrate transporters in other plant species. Numbers in the nods indicate bootstrap values calculated using 500 resampling.

Additional file 6: Table S4. Predicted maize MATE members clustered with citrate transporter from other plants, aminoacid sequence identity to SBMATE and the predicted physical position on the maize genome.

\section{Abbreviations}

Al: Aluminum; ALMT1: Aluminum-activated malate transporter; ALS: Aluminum sensitive; ART1: Al resistance transcription factor: BC2F3: Backcross 2 F3; bp: Base pair; CAPs: Cleaved amplified polymorphic sequence; Cl: Confidence interval; CNV: Copy number variation; eQTL: Expression quantitative trait loci; FRL: Final root length; GBS: Genotyping-by-sequencing; HvAACT1: Hordeum vulgare aluminumactivated citrate transporter; indel: Insertion/deletion; IRL: Initial root length; MAF: Minor allele frequency; MAGI: Maize assembled genomic island; MATE: Multidrug and toxic compound extrusion; Mbp: Mega base pairs; $\mu$ M: micro Molar; NIL: Near-isogenic line; Nramp: Natural resistance-associated macrophage protein; Nrat1: Nramp aluminum transporter; NRG_c: Net root growth in control conditions; OSFRDL4: Oryza sativa ferric reductase defective 4; PEV: Predicted error variance; $Q P C R$ : Quantitative real-time PCR;

QTL: Quantitative trait loci; RIL: Recombinant inbred line; RNRG: Relative net root growth; SEP: Standard error of the predicted genotypic values; SCFRDL2: Secale cereale ferric reductase defective 2; SNP: Single nucleotide polymorphism; SSEfm: Sum of squares of residuals from the full model; SSErm: Sum of squares of residuals from the reduced model; SSR: Simple sequence repeats; STAR: Sensitive to Al rhizotoxicity; STOP1: Sensitive to proton rhizotoxicity 1; STS: Sequence-tagged site; W/V: Weight per volume; ZmASL: Zea mays AltSB-like.

\section{Competing interests}

The authors declare that they have no competing interests.

\section{Authors' contributions}

Conceived and designed experiments: CTG, JVM, VMCA. Performed experiments: CCS, LGM, RCCV, UGPL, CFST, SNJB. Analyzed the data: MMP, LGM, LJMG, RWN, SNP, CTG. Wrote the paper: CTG, MMP, JVM, LGM, LVK. All authors read and approved the final manuscript.

\section{Acknowledgments}

JVM and CTG received fellowship from CNPq, CFST was supported by FAPEMIG. We thank Beatriz Barros for technical assistance in this study. This work was supported by The McKnight Foundation CCRP, IFS, FAPEMG, CAPES, CNPq, Generation Challenge Programme and Embrapa.

\section{Author details}

'Nucleus of Applied Biology, Embrapa Maize and Sorghum, Road MG424, km 65, Sete Lagoas, MG 35701-970, Brazil. ²Instituto de Ciências Biológicas, Universidade Federal de Minas Gerais, Belo Horizonte, MG, Brazil. ${ }^{3}$ Department of Plant Breeding and Genetics, Cornell University, Ithaca, NY, USA. ${ }^{4}$ Departamento de Biologia, Centro Universitário de Sete Lagoas, Sete Lagoas, MG, Brazil. ${ }^{5}$ Robert W. Holley Center for Agriculture and Health, U.S. Department of Agriculture - Agriculture Research Service, Cornell University, Ithaca, NY, USA.

Received: 1 November 2013 Accepted: 29 January 2014 Published: 24 February 2014

\section{References}

1. von Uexküll HR, Mutert E: Global extent, development and economic impact of acid soils. Plant Soil 1995, 71:1-15.
2. Kochian LV: Cellular mechanisms of aluminum toxicity and resistance in plants. Ann Rev Plant Biol 1995, 46:237-260.

3. Ciotta MN, Bayer C, Ernani PR, Fontoura SMV, Albuquerque JA, Wobeto C: Acidificacao de um latossolo sob plantio direto. Rev Bras Cien Solo 2002, 26:1055-1064.

4. Cassol AE, Denardin JE, Cochhann RA: Sistema plantio direto: evolucao e implicacoes sobre a conservacao do solo e da agua. In Topico em Ciencia do Solo. Edited by Ceretta CA, da Silva LS, Reichert JM. Vicosa: Sociedade Brasileira de Ciência do Solo; 2007:333-370.

5. Awika JM: Major cereal grains production and use around the world. In Advances in Cereal Science: Implications to Food Processing and Health Promotion. Edited by Awika JM, Piironen V, Bean S. Washington: American Chemical Society; 2011:1-13.

6. Sasaki T, Yamamoto Y, Ezaki B, Katsuhara M, Ahn SJ, Ryan PR, Delhaize E, Matsumoto $\mathrm{H}$ : A wheat gene encoding an aluminum-activated malate transporter. Plant J 2004, 37:645-653.

7. Magalhaes JV, Garvin DF, Wang Y, Sorrells ME, Klein PE, Schaffert RE, Li L, Kochian LV: Comparative mapping of a major aluminum tolerance gene in sorghum and other species in the Poaceae. Genetics 2004, 167:1905-1914.

8. Magalhaes JV, Liu J, Guimarães CT, Lana UGP, Alves VM, Wang YH, Schaffert RE, Hoekenga OA, Piñeros MA, Shaff JE, Klein PE, Carneiro NP, Coelho CM, Trick HN, Kochian LV: A gene in the multidrug and toxic compound extrusion (MATE) family confers aluminum tolerance in sorghum. Nat Genet 2007, 39:1156-1161.

9. Furukawa J, Yamaji N, Wang H, Mitani N, Murata Y, Sato K, Katsuhara M, Takeda K, Ma JF: An aluminum-activated citrate transporter in barley. Plant Cell Physiol 2007, 48:1081-1091.

10. Hoekenga OA, Maron LG, Piñeros MA, Cancado GM, Shaff J, Kobayashi Y, Ryan PR, Dong B, Delhaize E, Sasaki T, Matsumoto H, Yamamoto Y, Koyama H, Kochian LV: AtALMT1, which encodes a malate transporter, is identified as one of several genes critical for aluminum tolerance in Arabidopsis. Proc Natl Acad Sci USA 2006, 103:9738-9743.

11. Ligaba A, Katsuhara M, Ryan PR, Shibasaka M, Matsumoto M: The BnALMT1 and BnALMT2 genes from Brassica napus L. encode aluminum-activated malate transporters that enhance the aluminum resistance of plant cells. Plant Physiol 2006, 142:1294-1303.

12. Collins NC, Shirley NJ, Saeed M, Pallotta M, Gustafson JP: An ALMT1 gene cluster controlling aluminum tolerance at the Alt4 locus of rye (Secale cereale L). Genetics 2008, 179:669-682.

13. Liu J, Magalhaes JV, Shaff J, Kochian LV: Aluminum-activated citrate and malate transporters from the MATE and ALMT families function independently to confer Arabidopsis aluminum tolerance. Plant J 2009, 57:389-399.

14. Ryan PR, Raman H, Gupta S, Horst WJ, Delhaize E: A second mechanism for aluminium resistance in wheat relies on the constitutive efflux of citrate from roots. Plant Physiol 2009, 149:340-351.

15. Yokosho K, Yamaji N, Ma JF: Isolation and characterization of two MATE genes in rye. Funct Plant Biol 2010, 37:296-303.

16. Maron LG, Piñeros MA, Guimaraes CT, Magalhaes JV, Pleiman JK, Mao C, et al: Two functionally distinct members of the MATE (multidrug and toxic compound extrusion) family of transporters potentially underlie two major aluminum tolerance QTLs in maize. Plant J 2010, 61:728-740.

17. Yokosho K, Yamaji N, Ma JF: An Al-inducible MATE gene is involved in external detoxification of Al in rice. Plant J 2011, 68:1061-1069.

18. Hoekenga OA, Vision TJ, Shaff JE, Monforte AJ, Lee GP, Howell SH, Kochian $\mathrm{LV}$ : Identification and characterization of aluminum tolerance loci in arabidopsis (Landsberg erecta $x$ Columbia) by quantitative trait locus mapping: a physiologically simple but genetically complex trait. Plant Physiol 2003, 132:936-948.

19. Sibov ST, Gaspar MJ, Ottoboni LMM, Arruda P, Souza AP: Two genes controlling aluminum tolerance in maize: genetic and molecular mapping analyses. Genome 1999, 42:475-482

20. Ninamango-Cárdenas F, Guimaraes CT, Martins PR, Parentoni SN, Carneiro NP, Lopes MA, Moro JR, Paiva E: Mapping QTLs for aluminum tolerance in maize. Euphytica 2003, 130:23-232.

21. Conceicao LDHCS, Tessele C, Barbosa Neto JF: Diallel analysis and mapping of aluminum tolerance in corn inbred lines. Maydica 2009, 54:51-64.

22. Wu P, Liao CD, Hu B, Yi KK, Jin WZ, Ni JJ, He C: QTLs and epistasis for aluminum tolerance in rice (Oryza sativa L.) at different seedling stages. Theor Appl Genet 2000, 100:1295-1303. 
23. Ma JF, Shen R, Zhao Z, Wissuwa M, Takeuchi Y, Editani T, Yano M: Response of rice to $\mathrm{Al}$ stress and identification of quantitative trait loci for $\mathrm{Al}$ tolerance. Plant Cell Physiol 2002, 43:652-659.

24. Nguyen BD, Brar DS, Bui BC, Nguyen TB, Pham LN, Nguyen HT: Identification and mapping of the QTL for aluminum tolerance introgressed from the new source, Oryza rufipogon Griff., into indica rice (Oryza sativa L.). Theor App/ Genet 2003, 106:583-593.

25. Xue $Y$, Jiang L, Su N, Wang JK, Deng $P$, Ma JF, Zhai HQ, Wan JM: The genetic basic and fine-mapping of a stable quantitative-trait loci for aluminium tolerance in rice. Planta 2007, 227:255-262.

26. Famoso AN, Zhao K, Clark RT, Tung C, Wright MH, Bustamante C, Kochian LV, McCouch SR: Genetic architecture of aluminum tolerance in rice (Oryza sativa) determined through genome-wide association analysis and QTL mapping. PloS Genet 2011, 7:e1002221.

27. Larsen PB, Cancel J, Rounds M, Ochoa V: Arabidopsis ALS1 encodes a root tip and stele localized half type $A B C$ transporter required for root growth in an aluminum toxic environment. Planta 2007, 225:1447-1458.

28. Larsen PB, Geisler MJB, Jones CA, Williams KM, Cancel JD: ALS3 encodes a phloem-localized $A B C$ transporter-like protein that is required for aluminum tolerance in Arabidopsis. Plant J 2005, 41:353-363.

29. Huang CF, Yamaji N, Mitani N, Yano M, Nagamura Y, Ma JF: A bacterialtype $A B C$ transporter is involved in aluminum tolerance in rice. Plant Cell 2009, 21:655-667.

30. Huang CF, Yamaji N, Chen Z, Ma JF: A tonoplast-localized half-size ABC transporter is required for internal detoxification of $\mathrm{Al}$ in rice. Plant J 2012, 69:857-867.

31. Xia J, Yamaji N, Kasai T, Ma JF: Plasma membrane-localized transporter for aluminum in rice. Proc Natl Acad Sci USA 2010, 107:18381-18385.

32. luchi S, Koyama H, luchi A, Kobayashi Y, Kitabayashi S, Kobayashi Y, Ikka T, Hirayama T, Shinozaki K, Kobayashi M: Zinc finger protein STOP1 is critical for proton tolerance in Arabidopsis and coregulates a key gene in aluminum tolerance. Proc Natl Acad Sci USA 2007, 104:9900-9905.

33. Sawaki Y, luchi S, Kobayashi Y, Kobayashi Y, Ikka T, Sakurai N, Fujita M, Shinozaki K, Shibata D, Kobayashi M, Koyama H: STOP1 regulates multiple genes which protect Arabidopsis from proton and aluminum toxicities. Plant Physiol 2009, 150:281-294

34. Yamaji N, Huang CF, Nagao S, Yano M, Sato Y, Nagamura Y, Ma JF: A zinc finger transcription factor ART1 regulates multiple genes implicated in aluminum tolerance in rice. Plant Cell 2009, 21:3339-3349.

35. Magnavaca R, Graminer CD, Clark RB: Inheritance of aluminum tolerance in maize. In Genetic Aspects of Plant Mineral Nutrition. Edited by Gabeiman HW, Lougnmam BC. Dordrecht: Martinus Nijhoff; 1987:201-212.

36. Pandey S, Magnavaca R, Bahia Filho AFC, Dugue-Varges J, Vinasco LE: Genetics of tolerance to soil acidity in tropical maize. Crop Sci 1994 34:1511-1514.

37. Lima M, Miranda Filho JB, Furlani PR: Diallel cross among inbred lines of maize differing in aluminum tolerance. Brazil J Genet 1995, 4:579-584.

38. Pellet DM, Grunes DL, Kochian LV: Organic acid exudation as an aluminium-tolerance mechanism in maize (Zea mays L.). Planta 1995 196:788-795.

39. Piñeros MA, Magalhaes JV, Carvalho AVM, Kochian LV: The physiology and biophysics of an aluminum tolerance mechanism based on root citrate exudation in maize. Plant Physiol 2002, 129:1194-1206.

40. Piñeros MA, Shaff JE, Manslank HS, Alves VM, Kochian LV: Aluminum resistance in maize cannot be solely explained by root organic acid exudation. a comparative physiological study. Plant Physiol 2005 137:231-241.

41. Krill AM, Kirst M, Kochian LV, Buckler ES, Hoekenga OA: Association and linkage analysis of aluminum tolerance genes in maize. PloS One 2010 5:e9958.

42. Maron LG, Guimaraes CT, Kirst M, Albert PS, Birchler JA, Bradbury PJ, Buckle ES, Coluccio AE, Danilova TV, Kudrna D, Magalhaes JV, Piñeros MA, Schatz MC, Wingg RA, Kochian LV: Aluminium tolerance in maize is associated with higher MATE1 gene copy number. Proc Natl Acad Sci USA 2013, 110:5241-5246.

43. Ligaba A, Maron L, Shaff J, Kochian L, Piñeros M: Maize ZmALMT2 is a root anion transporter that mediates constitutive root malate efflux. Plant Cell Environ 2012, 35:1185-1200.

44. Elshire RJ, Glaubitz JC, Sun Q, Poland JA, Kawamoto K, Buckler ES, Mitchell SE: A robust, simple genotyping-by-sequencing (GBS) approach for high diversity species. PloS One 2011, 6:e19379.
45. Hund A, Frachboud Y, Soldati A, Frascaroli E, Salvi S, Stamp P: QTL controlling root and shoot traits of maize seedlings under cold stress. Theor Appl Genet 2004, 109:618-629.

46. Zhu JM, Mickelson SM, Kaeppler SM, Lynch JP: Detection of quantitative trait loci for seminal root traits in maize (Zea mays L.) seedlings grown under differential phosphorus levels. Theor Appl Genet 2006, 113:1-10.

47. Hund A, Reimer R, Messmer R: A consensus map of QTLs controlling the root length of maize. Plant Soil 2011, 344:143-158.

48. Brondani C, Paiva E: Análise de RFLP da tolerância à toxidez do alumanio no cromossomo 2 de milho. Pesqui Agropecu Bras 2004, 31:575-579.

49. Maron LG, Kirst M, Mao C, Milner MJ, Menossi M, Kochian LV: Transcriptional profiling of aluminum toxicity and tolerance responses in maize roots. New Phytol 2008, 179:116-128.

50. Melo JO, Lana UG, Piñeros MA, Alves VM, Guimarães CT, Liu J, Zheng Y, Zhong S, Fei Z, Maron LG, Schaffert RE, Kochian LV, Magalhaes JV: Incomplete transfer of accessory loci influencing SbMATE expression underlies genetic background effects for aluminum tolerance in sorghum. Plant J 2013, 73:276-288.

51. Paterniani E, Goodman MM: Races of Maize in Brazil and Adjacent Areas. International Maize and Wheat Improvement Center: Mexico DF; 1977.

52. Naspolini Filho W, Bahia Filho AFC, Vianna RT, Gama EEG, Vasconcellos CA, Magnavaca R: Comportamento de linhagens e híbridos simples de milho (Zea mays L.) em solo sob vegetação de cerrado. Cienc Cult 1981, 33:722-727

53. Magnavaca R: Genetic variability and the inheritance of aluminum tolerance in maize (Zea mays L.). In PhD thesis. Lincoln: University of Nebraska, Agronomy Department; 1982.

54. Sawazaki E, Furlani PR: Tolerância ao alumínio em milho Cateto. Bragantia 1987, 46:269-278.

55. Moon D, Ottoboni L, Souza AP, Sibov S, Gaspar M, Arruda P: Somaclonal variation-induced aluminum-sensitive mutant from an aluminum-inbred maize tolerant line. Plant Cell Rep 1997, 16:686-691.

56. Mattiello L, Kirst M, da Silva F, Jorge R, Menossi M: Transcriptional profile of maize roots under acid soil growth. BMC Plant Biol 2010, 10:196.

57. McCouch S, Baute GJ, Bradeen J, Bramel P, Bretting PK, Buckler E, Burke JM, Charest D, Cloutier S, Cole G, Dempewolf H, Dingkuhn M, Feuillet C, Gepts P, Grattapaglia D, Guarino L, Jackson S, Knapp S, Langridge P, Lawton-Rauh A, Lijua Q, Lusty C, Michael T, Myles S, Naito K, Nelson RL, Pontarollo R, Richards CM, Rieseberg L, Ross-lbarra J, et al: Agriculture: feeding the future. Nature 2013, 499:23-24.

58. Lu Y, Yan J, Guimarães CT, Taba S, Hao Z, Gao S, Chen S, Li J, Zhang S, Vivek BS, Magorokosho C, Mugo S, Makumbi D, Parentoni SN, Shah T, Rong T, Crouch $\mathrm{H}, \mathrm{Xu} Y$ : Molecular characterization of global maize breeding germplasm based on genome-wide single nucleotide polymorphisms. Theor Appl Genet 2009, 120:93-115.

59. Parentoni SN, Magalhaes JV, Pacheco CAP, Santos MX, Abadie T, Gama EEG, Guimarães PEO, Meirelles WF, Lopes MA, Vasconcelos MJV, Paiva E: Heterotic groups based on yield-specific combining ability data and phylogenetic relationship determined by RAPD markers for 28 tropical maize open pollinated varieties. Euphytica 2001, 121:197-208.

60. Machado Filho MAP, Matias AB: Embrapa Unimilho: franquia em genetica vegetal. Rev Admin 1995, 30:51-64.

61. Shaff JE, Schultz BA, Craft EJ, Clark RT, Kochian LV: GEOCHEM-EZ: a chemical speciation program with greater power and flexibility. Plant Soil 2010, 330:207-214.

62. Cruz CD: GENES: a software package for analysis in experimental statistics and quantitative genetics. Acta Sci 2013, 35:271-276.

63. Saghai-Maroof MA, Soliman KM, Jorgensen RA, Allard RW: Ribosomal DNA spacer length polymorphism in barley: mendelian inheritance, chromosomal location and population dynamics. Proc Natl Acad Sci USA 1984, 81:8014-8018.

64. Fu Y, Emrich SJ, Guo L, Wen T-J, Ashlock DA, Aluru S, Schnable PS: Quality assessment of maize assembled genomic islands (MAGIs) and large-scale experimental verification of predicted genes. Proc Natl Acad Sci USA 2005, 102:12282-12287.

65. Roberts A, McMillan L, Wang W, Parker J, Rusyn I, Threadgill D: Inferring missing genotypes in large SNP panels using fast nearest-neighbor searches over sliding windows. Bioinformatics 2007, 23:i401-i407.

66. Bradbury PJ, Zhang Z, Kroon DE, Casstevens TM, Ramdoss Y, Buckler ES: TASSEL: software for association mapping of complex traits in diverse samples. Bioinformatics 2007, 23:2633-2635. 
67. Kao $\mathrm{CH}$, Zeng $\mathrm{ZB}$, Teasdale RD: Multiple interval mapping for quantitative trait loci. Genetics 1999, 152:1203-1216.

68. R Core Team: R Language and Environment for Statistical Computing. In RFoundation for Statistical Computing. D [http://www.R-project.org]

69. Livak KJ, Schmittgen TD: Analysis of relative gene expression data using realtime quantitative PCR and the $2^{-\triangle \triangle C}$ method. Methods 2001, 25:402-408.

70. Tamura K, Peterson D, Peterson N, Stecher G, Nei M, Kumar S: MEGA5: Molecular evolutionary genetics analysis using maximum likelihood, evolutionary distance, and maximum parsimony methods. Mol Biol Evol 2011, 28:2731-2739.

71. Resende MDV: Software Selegen - REML/BLUP: Sistema Estatastico e Selecao Genetica Computadorizada via Modelos Lineares Mistos. Embrapa Florestas: Colombo; 2007

doi:10.1186/1471-2164-15-153

Cite this article as: Guimaraes et al:: Genetic dissection of Al tolerance QTLs in the maize genome by high density SNP scan. BMC Genomics 2014 15:153.

\section{Submit your next manuscript to BioMed Central and take full advantage of:}

- Convenient online submission

- Thorough peer review

- No space constraints or color figure charges

- Immediate publication on acceptance

- Inclusion in PubMed, CAS, Scopus and Google Scholar

- Research which is freely available for redistribution 